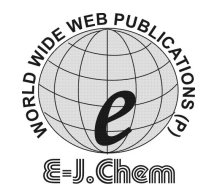

http://www.e-journals.net

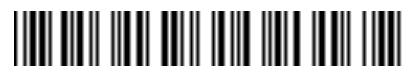

ISSN: 0973-4945; CODEN ECJHAO

E-Journal of Chemistry

Vol. 4, No. 4, pp. 480-486, October 2007

\title{
Spectrophotometric Determination of Fenpropathrin in its Formulations and Water Samples
}

\author{
B. KRISHNA PRIYA, P. SUBRAHMANYAM, \\ K.DAKSHAYANI and P. CHIRANJEEVI* \\ *Environmental Monitoring Laboratory, Department of Chemistry, \\ "Department of Mathematics, S. V. University, Tirupati - 517 502, A. P., India. \\ chiranjeevipattium@gmail.com
}

Received 2 February 2007; Accepted 4 March 2007

\begin{abstract}
Novel spectrophotometric methods were developed for the determination of fenpropathrin in insecticidal formulations and water samples. The methods were based on the hydrolysis of fenpropathrin with ethanolic $\mathrm{KOH}$ to form 3-phenoxy benzaldehyde. The resultant aldehyde group was condensed with anthranilic acid in presence of basic medium to form yellowish red color product having $\lambda_{\max }$ of $485 \mathrm{~nm}$ or condensed with 2-chloro phenyl hydrazine to form pink color product having $\lambda_{\max }$ of $557 \mathrm{~nm}$. The color derivatives were correspondingly stable for 5 and 8 days. The Beer's law was obeyed over the range from $0.03-10.0 \mu \mathrm{g} \mathrm{mL}^{-1}$ and molar absorptivity $2.586 \mathrm{x}$ $10^{4} 1 \mathrm{~mol}^{-1} \mathrm{~cm}^{-1}$ for anthranilic acid and from $0.02-8.0 \mu \mathrm{g} \mathrm{mL}^{-1}$ and molar absorptivity $3.924 \times 10^{4} 1 \mathrm{~mol}^{-1} \mathrm{~cm}^{-1}$ for 2-chloro phenyl hydrazine were observed. The optimum reaction conditions and other analytical parameters were established. The proposed methods have been applied for the analysis of water samples.
\end{abstract}

Keywords: Fenpropathrin, Anthranilic acid, 2-Chloro phenyl hydrazine, Spectrophotometry, Water Samples

\section{Introduction}

Fenpropathrin is a synthetic pyrethroid and possess high insecticidal activity. It is used to control many species of mites and insects like whiteflies, cotton field crops, glass house crops, vegetables. Appreciable levels of pyrethroid residues can occur in food commodities from crops, food of animal origin (eg. milk, eggs and meat), soils, sediments, and surface, ground and drinking water ${ }^{1}$. Pyrethroids are now employed worldwide as insecticides, 
agriculture, forestry, public health and domestic activity due to their insectidal activity,bio transformation and most importantly non-persistance in their environment. Their nonpersistance is essentially due to photodegradation which occurs via decarbaxylation, ester bond cleavage and hydration of cyano group to carbaxamide ${ }^{2}$. How ever, high toxicity to fish, aquatic species, and honeybees was observed for more pyrethroids ${ }^{3}$. Contamination of fresh-water ecosystems occurs either because of the direct discharge of industrial and agricultural effluents or as a result of effluents from sewage treatment works, residues can thus accumulate in the surrounding biosphere ${ }^{4}$.

Several analytical techniques have been reported for the determination of fenpropathrin which includes GC-ECD ${ }^{5}$, Electron capture method ${ }^{6}$, HPLC $^{7}$, coupled column liquid chromatography ${ }^{8}$, capillary GC-MS ${ }^{9}$ and FT-IR ${ }^{10}$. These techniques required large number of solvents for the extractions and also some limitations in terms of high cost of instruments used in routine analysis and matrix effects. Spectrophotometric method is still one of the important techniques for the determination of pesticides because it is less expensive and easy to use.

The present investigation is to provide a simple spectrophotometric technique for the determination of fenpropathrin based on condensation of resultant aldehyde group with anthranilic acid, 2- chloro phenyl hydrazine. The developed methods have been successfully employed for the determination of fenpropathrin in its formulations, water samples.

\section{Experimental}

\section{Instrumentation}

A HITACHI U 2001 spectrophotometric with $1.0 \mathrm{~cm}$ matched quartz cells were used for all absorbance measurement. An Elico Li-29 model pH metre with combined glass electrode was used for $\mathrm{pH}$ measurements.

\section{Reagents and materials}

Technical grade samples of fenpropathrin were obtained from Bayer India limited. India. $0.25 \%$ of anthranilic acid , 2- chloro phenyl hydrazine was prepared by dissolving $0.25 \mathrm{~g}$, in $100 \mathrm{~mL}$ methanol. Fenpropathrin stock solution was prepared by dissolving appropriate amount of fenpropathrin in $100 \mathrm{~mL}$ acetonitrile. $10 \mathrm{~mL}$ of this solution was subsequently diluted to $100 \mathrm{~mL}$ acetonitrile. Fenpropathrin stock solution was preserved at $4{ }^{\circ} \mathrm{C}$ in a refrigerator and desired concentrations were prepared freshly. An amount of $3.4 \mathrm{~mL}$ concentrated sulphuric acid is added to $250 \mathrm{~mL}$ distilled water in a $500 \mathrm{~mL}$ flask. $25 \mathrm{~g}$ of monopotassium di hydrogen phosphate is added to this, shaken until dissolution is complete and diluted to $500 \mathrm{~mL}$ for $\mathrm{pH} 8.0$.

\section{General procedure}

Transfer $0.5-3.5 \mathrm{~mL}$ portions of fenpropathrin $(10 \mu \mathrm{g} / \mathrm{mL})$ solution of insecticide solutions into a clean dry $50 \mathrm{~mL}$ beaker. $4 \mathrm{~mL}$ of $2 \%$ ethanolic potassium hydroxide solution was added and allowed to stand for $7 \mathrm{~min}$ for complete hydrolysis, heated $40-45{ }^{\circ} \mathrm{C}$ for $45 \mathrm{~min}$ and neutralised with $0.1 \mathrm{~N} \mathrm{HCl}, 2 \mathrm{~mL}$ of $0.25 \%$ of anthranilic acid was added followed by one drop of concentrated $\mathrm{HCl}$ and heated to $50-55^{\circ} \mathrm{C}$ for $30 \mathrm{~min}$ for color development. The same procedure was carried out for of 2- chloro phenyl hydrazine. The absorbance of the color derivatives were measured at $\lambda_{\max } 485 \mathrm{~nm}$ for of anthranilic acid, $557 \mathrm{~nm}$ for 2chloro phenyl hydrazine against reagent blank as shown in Figure 1. The formation of color derivatives was shown in Scheme.1. 
<smiles></smiles>

Fenpropathrin<smiles>CC(C)[C@@H]1C(C(=O)[O-])C1(C)C</smiles>

Acid<smiles>N#CC(O)c1cccc(Oc2ccccc2)c1</smiles>

cyanohydrin<smiles></smiles>

3-phenoxybenzaldehyde

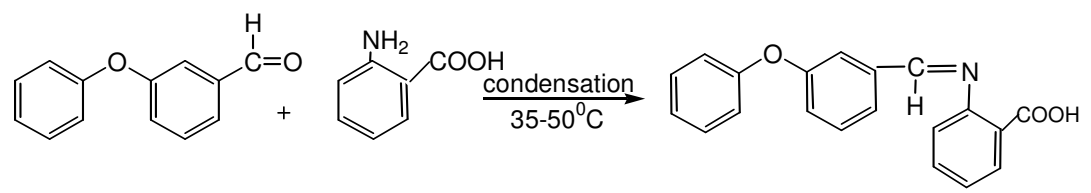

3-phenoxybenzaldehyde Anthranilic acid Yellowish red color compound<smiles>NNc1ccccc1Cl</smiles>

3-phenoxybenzaldehyde 2-chlorophenylhydrazine

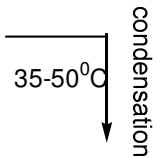<smiles>N=Cc1cccc(Oc2ccccc2)c1</smiles>

Pink color compound

Scheme.1 Color product of the fenpropathrin with anthranilic acid and 2-chlorophenyl hydrazine

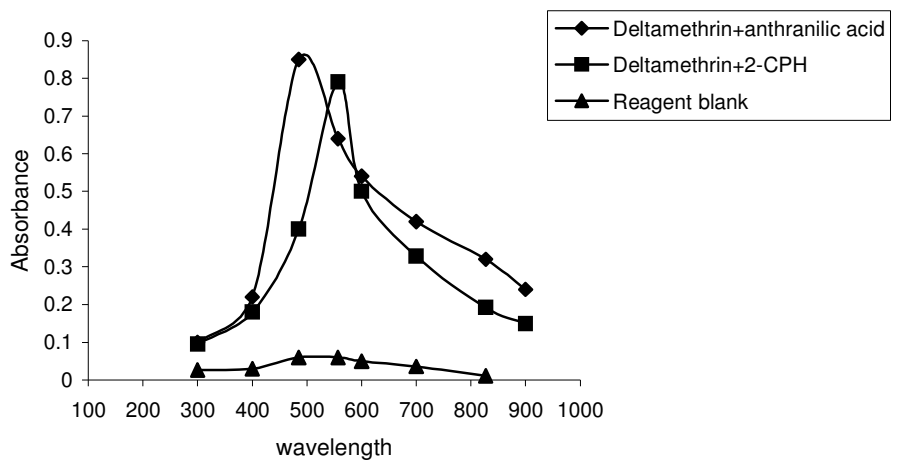

Fig.1. Absorption spectra of fenpropathrin with the reagents 


\section{Determination of fenpropathrin in their formulations}

$3 \mathrm{~mL}(50 \mathrm{mg}$ ) of fenpropathrin insecticide formulation was placed in a procelain dish, and $20 \mathrm{~mL}$ of methanol was added. This mixture was stirred well and heated the samples on a hot water bath then evaporated the solvent. The procedure was repeated five times, and the resulting solution was diluted to $50 \mathrm{~mL}$ with methanol in a calibrated flask. The fenpropathrin was determined by the above procedure. The results were shown in Table 2.

\section{Determination of fenpropathrin in water samples}

The tap and river water samples were fortified with concentrations in the ranges from $0.5-$ 3.0 and $0.7-4.2 \mathrm{ppm}$ in methanol for two methods, under study which are presented in the Table 3 and 4 respectively. Apart from the synthetic pesticide standards in n-hexane, aqueous samples were analysed with liquid-liquid extraction. Fresh water samples of river and tap water collected in amber glass bottles. A volume of $1 \mathrm{~mL}$ of $0.1 \mathrm{M} \mathrm{Na} \mathrm{Na}_{2} \mathrm{~S}_{3}$ per litre of water sample was added on site to suppress the interferences of chloride, humic acid, fulvic acids. All samples were filtered through a micro seperations in $0.45 \mu$ m nylon filter to remove particulate matter. In order to avoid degradation of some of the pesticides under alkaline conditions ${ }^{11}$, the $\mathrm{pH}$ of the all water samples was adjusted to 5-6. Finally, extracts were evaporated to dryness on a steam bath and the residue was dissolved in $\mathrm{MeOH}$. The amount was determined according to aforesaid procedure.

\section{Results and Discussion}

The method involved in alcohol alkaline hydrolysis of fenpropathrin to form 3phenoxy benzaldehyde followed by condensation with anthranilic acid and 2-chloro phenyl hydrazine. The hydrolyzed fenpropathrin forms yellowish red and pink derivative with anthranilic acid, 2-chloro phenyl hydrazine in basic medium of $\mathrm{pH}$ 8-9 (as shown in Figure 2.) having $\lambda_{\max } 485$ and $557 \mathrm{~nm}$. The corresponding reagent blanks have practically negligible absorbance at these wavelengths.

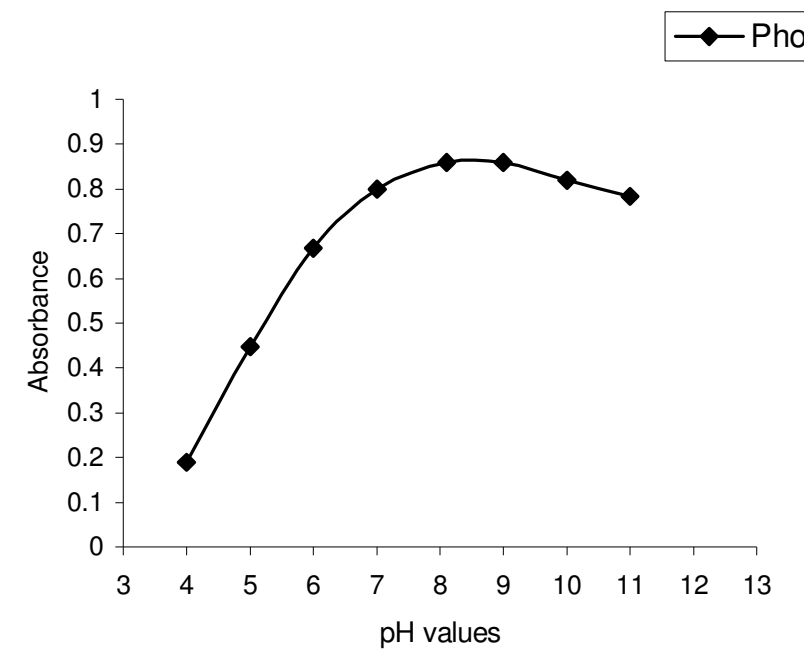

Fig.2. Effect of $\mathrm{pH}$ on fenpropathrin with anthranilic acid and 2-CPH 


\section{Analytical data}

The optical characteristics, precision and accuracy data was shown in Table 1. Limit of quantification (LOQ) is given by the relation $3 \sigma / \mathrm{s}$ and limit of detection is $3 \sigma / \mathrm{s}$, where $\sigma$ is the standard deviation of the blank with respect to water and $s$ is the slope of the calibration curve. Naturally, the limit of quantification slightly crosses the lower limit of Beer's law range. But, limit of detection is well below the lower limit of Beer's law range. The upper limit of the Beer-Lambert range is determined by a plot of absorbance against concentration at the volume of $\lambda_{\max }$. The Beer's law limits, molar absorptivity, Sandell's sensitivity, slope, intercept, correlation coefficient and optimum concentration range by photometric determinations are summarised in Table 1.

Table. 1. Optical characteristics, precision and accuracy of the present method

\begin{tabular}{|c|c|c|}
\hline Optical characteristics & Anthranilic acid & 2-Chloro phenyl hydrazine \\
\hline Concentration range, $\mu \mathrm{g} \mathrm{mL}^{-1}$ & $0.03-10.0$ & $0.02-8.0$ \\
\hline$\lambda_{\max }, \mathrm{nm}$ & 485 & 557 \\
\hline Color & Yellowish red & Pink \\
\hline Limit of Detection, $\mu \mathrm{g} \mathrm{mL}^{-1}$ & 0.039 & 0.046 \\
\hline Limit of Quantification, $\mu \mathrm{g} \mathrm{mL}^{-1}$ & 4.163 & 4.349 \\
\hline Stability of the color, days & 5 & 8 \\
\hline Molar absorptivity, $\mathrm{L} \mathrm{mol}^{-1} \mathrm{~cm}^{-1}$ & $2.586 \times 10^{4}$ & $3.924 \times 10^{4}$ \\
\hline Sandell's sensitivity, $\mu \mathrm{g} \mathrm{cm}^{-2}$ & 0.0205 & 0.0236 \\
\hline Regression equation, $Y=b x+a)$ & 0.1057 & \\
\hline Slope (b) & 0.0386 & 0.1282 \\
\hline Intercept (a) & & 0.0409 \\
\hline Standard deviation (S.D.) ${ }^{\mathrm{a}}$ & 0.587 & 0.662 \\
\hline Correlation coefficient & 0.9994 & 0.9986 \\
\hline Relative error, $\%$ & 0.12 & 0.27 \\
\hline
\end{tabular}

${ }^{\mathrm{a}}$ Calculation for five samples containing same amount of fenpropathrin, Where $\mathrm{x}$ is the concentration in $\mu \mathrm{g} \mathrm{mL} L^{-1}$.

\section{Effect of forgein ions}

The water samples $(500 \mathrm{~mL})$ were fortified with known amounts of fenpropathrin dissolved in $5 \mathrm{~mL}$ methanol. Known amounts of benzaldehyde dissolved in $10 \mathrm{~mL}$ of methanol were added, and the $\mathrm{pH}$ of each solution was adjusted to between 4 and 6 with $50 \%$ sulphuric acid. $10 \mathrm{~g}$ of $\mathrm{Na}_{2} \mathrm{SO}_{4}$ was dissolved in each sample and the fenpropathrin along with the aldehyde was extracted three times using $50 \mathrm{~mL}$ of chloroform for each extraction. The extracts were combined and placed in a $500 \mathrm{~mL}$ round bottom flask into which $100 \mathrm{mg} m$-chloroperbenzoic acid was dissolved. The resulting solution was refluxed on a hot water bath for a $15 \mathrm{~min}$ to convert the aldehyde into an acid. Thereafter, the solution was cooled, washed three times with $25 \mathrm{~mL}$ of 0.2 $\mathrm{M} \mathrm{Na}_{2} \mathrm{CO}_{3}$ solution per wash to remove the acid and unreacted $m$-chloroperbenzoic acid. Finally, washed 3 to 5 times with distilled water suing $50 \mathrm{~mL}$ for each 5 washing to remove excess carbonate. The chloroform solution was then dried over $10 \mathrm{~g}$ of anhydrous $\mathrm{Na}_{2} \mathrm{SO}_{4}$ and the solvent was evaporated by exposure to air. The residue obtained was dissolved in $\mathrm{MeOH}$ and then diluted to $250 \mathrm{~mL}$ with methanol in a calibration flask. Known amounts of this solution were placed in $25 \mathrm{~mL}$ conical flask. The determination of fenpropathrin was carried out with the anthranilic acid, 2-chloro phenylhydrazine . 
Table 2. Determination of fenpropathrin insecticide in formulations.

\begin{tabular}{ccccc}
\hline \multirow{2}{*}{$\begin{array}{c}\text { Technical Grade } \\
\text { Fenpropathrin }\end{array}$} & \multicolumn{2}{c}{ Anthranilic acid } & \multicolumn{2}{c}{ 2- Chlorophenyl hydrazine } \\
\cline { 2 - 5 } & $\begin{array}{c}\text { Indicated } \\
\text { label \% }\end{array}$ & Found \% & $\begin{array}{c}\text { Indicated label } \\
\%\end{array}$ & Found \% \\
\hline Oil Spray & 1 & 0.96 & 1 & 0.95 \\
EC & 10 & 9.82 & 10 & 9.85 \\
EC & 20 & 19.79 & 20 & 19.83 \\
\hline
\end{tabular}

Table 3. Estimation of fenpropathrin in fortified water samples using anthranilic acid

\begin{tabular}{|c|c|c|c|c|c|}
\hline \multirow{3}{*}{$\begin{array}{l}\text { Sample } \\
\text { number }\end{array}$} & \multirow{3}{*}{$\begin{array}{c}\text { Fortifica } \\
\text { - tion } \\
\text { level } \\
\text { ppm }\end{array}$} & \multicolumn{4}{|c|}{ Water samples } \\
\hline & & \multicolumn{2}{|c|}{ Tap water } & \multicolumn{2}{|c|}{ River water } \\
\hline & & $\begin{array}{c}\text { Amount } \\
\text { ppm }\end{array}$ & $\begin{array}{c}\text { Recovery } \\
\%\end{array}$ & $\begin{array}{c}\text { Amount } \\
\text { ppm }\end{array}$ & $\begin{array}{c}\text { Recovery } \\
\%\end{array}$ \\
\hline 1 & 0.7 & 0.69 & 98.57 & 0.68 & 97.17 \\
\hline 2 & 1.4 & 1.37 & 97.85 & 1.38 & 98.60 \\
\hline 3 & 2.1 & 2.07 & 98.57 & 2.05 & 97.61 \\
\hline 4 & 2.8 & 2.77 & 98.92 & 2.74 & 97.85 \\
\hline 5 & 3.5 & 3.46 & 98.85 & 3.49 & 99.71 \\
\hline 6 & 4.2 & 4.12 & 98.09 & 4.16 & 99.04 \\
\hline Average & & & 98.47 & & 98.33 \\
\hline
\end{tabular}

Table 4 . Estimation of fenpropathrinin fortified water samples using 2-chloro phenyl hydrazine

\begin{tabular}{|c|c|c|c|c|c|}
\hline \multirow{3}{*}{$\begin{array}{l}\text { Sample } \\
\text { number }\end{array}$} & \multirow{3}{*}{$\begin{array}{l}\text { Fortifica- } \\
\text { tion level } \\
\text { ppm }\end{array}$} & \multicolumn{4}{|c|}{ Water samples } \\
\hline & & \multicolumn{2}{|c|}{ Tap water } & \multicolumn{2}{|c|}{ River water } \\
\hline & & $\begin{array}{c}\text { Amount } \\
\text { ppm }\end{array}$ & $\begin{array}{c}\text { Recovery } \\
\%\end{array}$ & $\begin{array}{c}\text { Amount } \\
\text { ppm }\end{array}$ & $\begin{array}{c}\text { Recovery } \\
\%\end{array}$ \\
\hline 1 & 0.5 & 0.48 & 96.00 & 0.49 & 98.00 \\
\hline 2 & 1.0 & 0.98 & 98.00 & 0.96 & 96.00 \\
\hline 3 & 1.5 & 1.47 & 98.00 & 1.48 & 98.66 \\
\hline 4 & 2.0 & 1.97 & 98.50 & 1.95 & 97.50 \\
\hline 5 & 2.5 & 2.48 & 99.20 & 2.47 & 98.80 \\
\hline 6 & 3.0 & 2.97 & 99.00 & 2.98 & 99.33 \\
\hline Average & & & 98.20 & & 98.05 \\
\hline
\end{tabular}

\section{Conclusions}

The color of derivatives of fenpropathrin with anthranilic acid and 2-chloro phenylhydrazine is stable at room temperature of 5 and 8 days. The proposed method is simple, rapid and can be used for the determination of fenpropathrin in trace amounts. When compared with the literature method as summarized in Table 5. Interference from many substances other than aldehyde is eliminated by the selective extraction procedure used and also by measuring the absorbance of the sample against that of a corresponding crop control (blank). Additional advantages of these methods are that color develop instantaneously and are stable for long 
Table 5. Comparison of present method with the reported methods

\begin{tabular}{|c|c|c|c|c|c|c|c|c|c|c|}
\hline \multirow[b]{2}{*}{$\begin{array}{l}\frac{o}{2} \\
\text { 芯 } \\
\stackrel{n}{n}\end{array}$} & \multirow{2}{*}{ 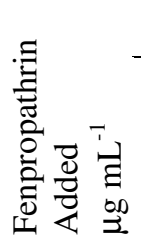 } & \multicolumn{4}{|c|}{ Anthranilic acid } & \multicolumn{4}{|c|}{ 2-Chloro phenyl hydrazine } & \multirow[b]{2}{*}{ 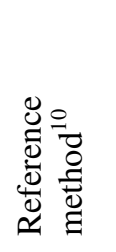 } \\
\hline & & 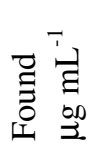 & 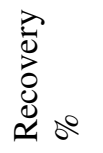 & 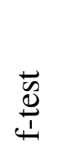 & 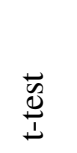 & 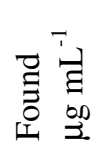 & 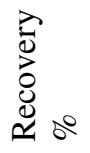 & $\underset{\Psi}{\vec{\omega}}$ & $\stackrel{\overrightarrow{\tilde{\omega}}}{\underline{\Delta}}$ & \\
\hline $\begin{array}{c}\text { Tap } \\
\text { water }\end{array}$ & 5 & 5.09 & 101.8 & 0.68 & 0.41 & 5.04 & 100.8 & 0.98 & 0.27 & $102 \pm 7$ \\
\hline $\begin{array}{l}\text { River } \\
\text { water }\end{array}$ & 10 & 9.97 & 99.7 & 0.52 & 0.26 & 9.95 & 99.5 & 0.61 & 0.34 & $89 \pm 3$ \\
\hline
\end{tabular}

period of time. Thus excess reagent has no effect on the absorbance of the colored derivatives. Moreover, this method do not involve the elaborate cleanup procedures and can be suitably adopted for routine check-up of the purity of fenpropathrin in their formulations, water samples. The performance of the proposed method was compared statistically in terms of student's ' $t$ ' test and the variance ratio of ' $\mathrm{f}$ '-test. The ' $f$ ' and ' $t$ ' test indicates the significance of the proposed method with the reference method ${ }^{10}$.

\section{Acknowledgments}

The authors are grateful to Rallis India Limited, Bangalore for supplying formulations and to the Head, Department of Biotechnology, S. V. University, Tirupati, for providing spectrophotometry facility.

\section{References}

1. Galera M, Vidal J.L, Frenich A and Garcia M D, J. Chromatogr.A, 1996, 727, 39.

2. Takahasi N, Mikami N, Yamada H and Miyamoto J, Pestic.Sci, 1985, 16, 119.

3. Ray D E, Hayesand W J and Laws E R (Ed.), Hand book of pesticde Toxicology, Classes of pesticides, 1991, Vol.2, p.585, Academic press, London.

4. Yasin M, Baugh P J, Bonwick G A, Davies D H, Hancock P and Leinoudi M, J.Chromatogr. A, 1996, 754, 235.

5. Colume A, Cardenas S, Gallego M and Valcarcel M, J.Chromatogr. A, 2001, 912, 83.

6. $\quad$ Ebing W, Fresenius Z. Anal.Chem, 1987, 327, 539.

7. Leon - Gonzolez M E, Plaza - Arroyo M, Perez - Arribos L V, Polo - Diez LM, Anal.Bio. anal.Chem, 2005, 382, 527.

8. Parrille Vazquez P, Gil Garcia M D, Barranco Martinez D and Martinez Galera M, Anal.Bio. anal.Chem, 2005, 381, 1217.

9. Serodio P and Nagueira J M F, Anal.Bio. anal.Chem, 2005, 382, 1141.

10. Colume A, Diework J and Lendl B, Intern.J.Environ.Anal.Chem, 2004, 84, 835.

11. Edelmann A, Diework J, Schuster K C and Lendl B, J. Agric. Food.Chem, 2001, 49, 1139. 


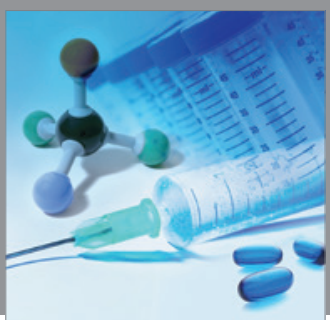

International Journal of

Medicinal Chemistry

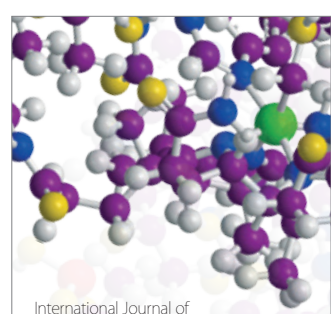

Carbohydrate Chemistry

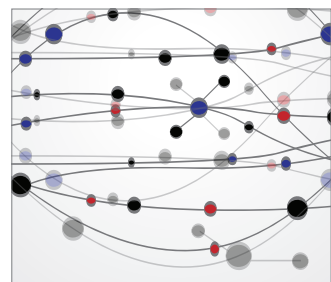

The Scientific World Journal
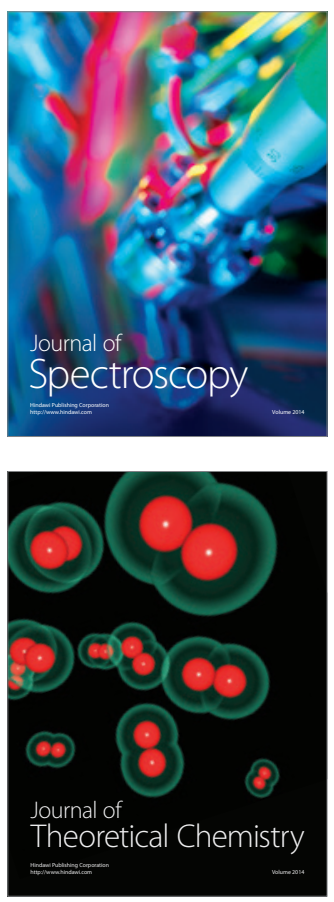
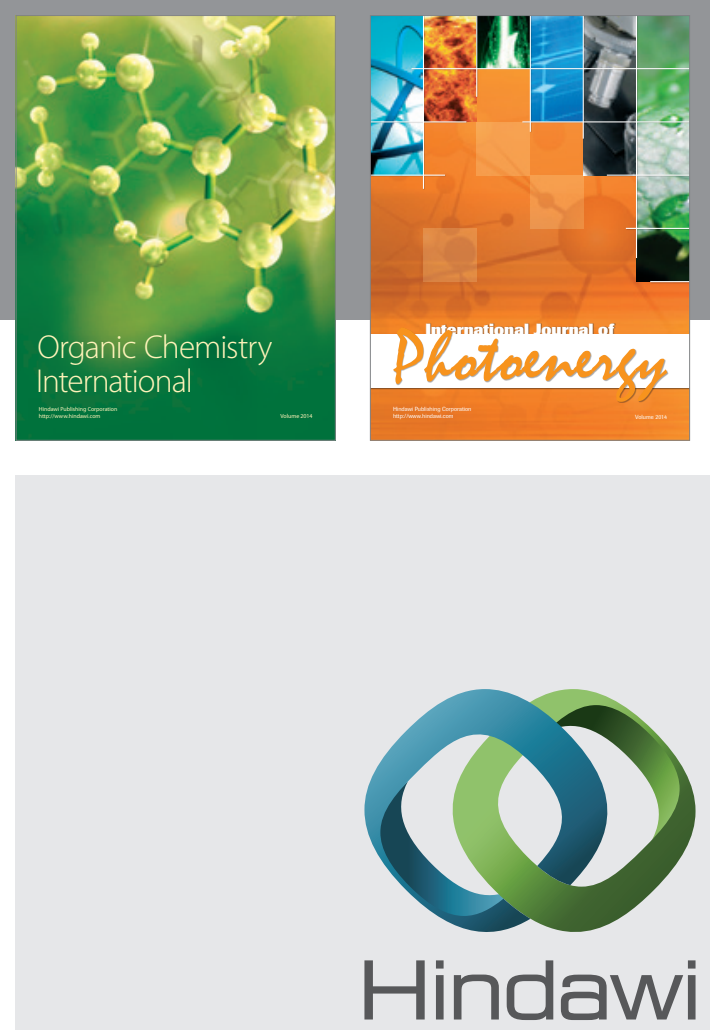

Submit your manuscripts at

http://www.hindawi.com
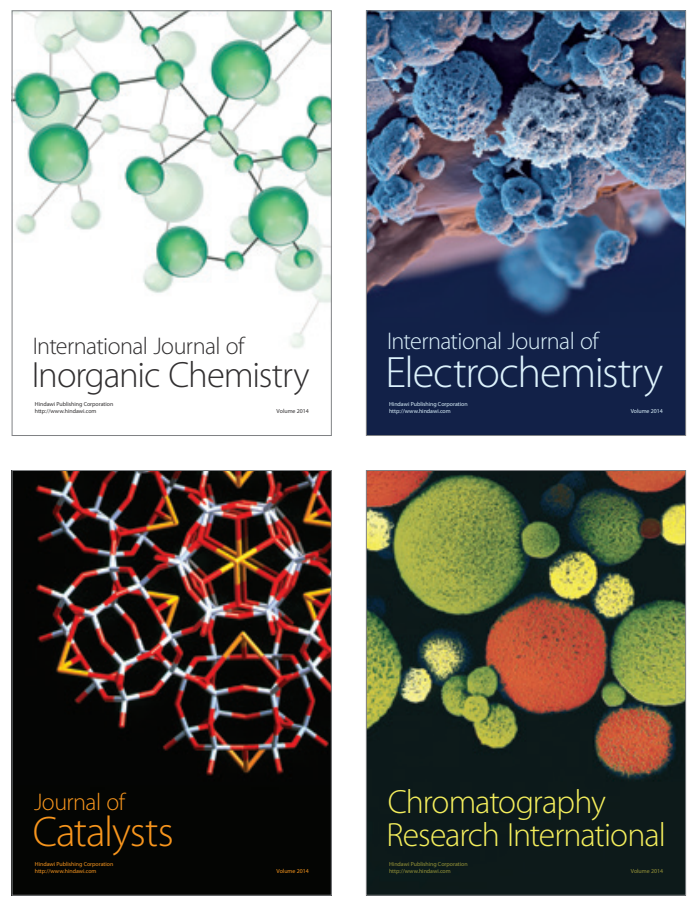
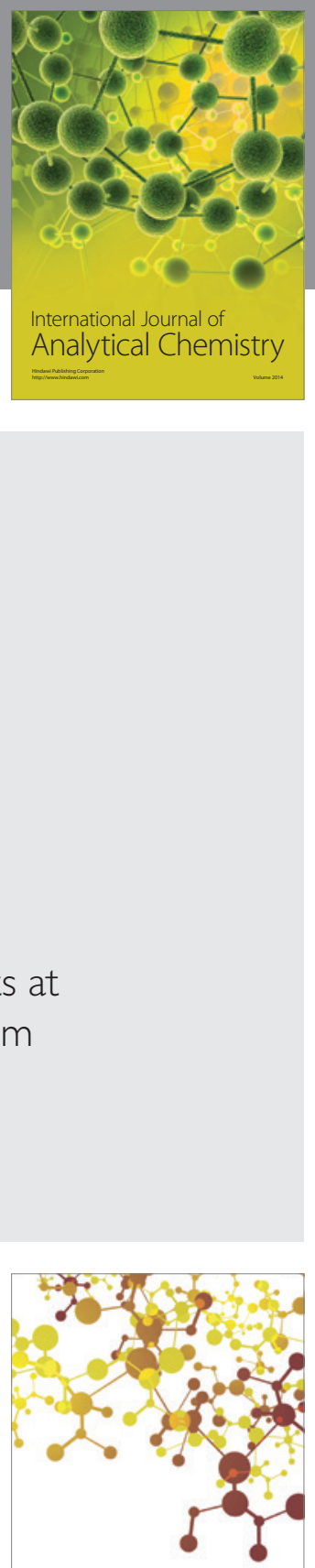

Journal of

Applied Chemistry
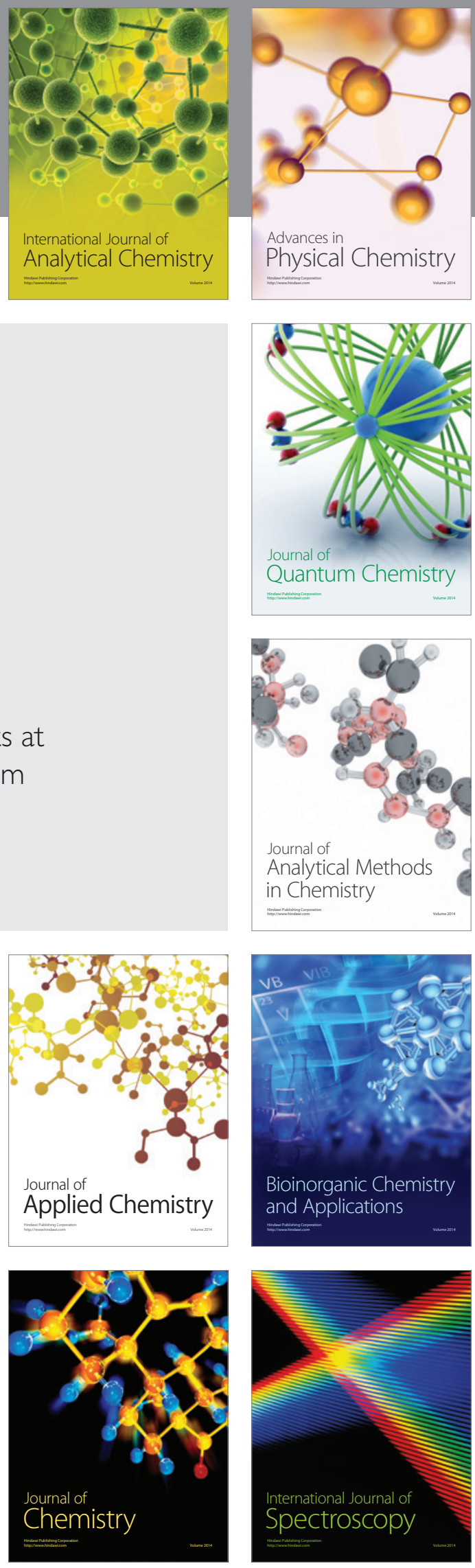